\title{
HISTORICO DE ENFERMAGEM: COMPREENSÃO E UTILIZAÇÃO TEÓRICO-PRÁTICA
}

\author{
Maria Luiza Anselmi• \\ Emilia Campos de Carvalho*• \\ Emilia Luigia Saporiti Angerami*an
}

\begin{abstract}
ANSELMI, M.L.; CARVALHO, E.C.; ANGERAMI, E.L.S. Historico de Enfermagem: compreensâo e utilizaço teórico-prática. Rev. Esc. Enj. USP. Săo Paulo, 22(2):181-188, ago. 1988.

O presente trabalho aborda a problemática da terminologia em enfermagem e seu emprego na prdica. Trata primordialmente do termo Histórico de Enfermagem, analisando seu surgimento e seus significados.
\end{abstract}

UNITERMOS: Historico de enfermagem. Processo de enfermagem.

\section{INTRODUÇÃO}

A enfermagem, na sua evoluçăo histórica, sofreu modificações imprimidas pelas transformaçðes ocorridas na estrutura económica, política e social, e que, no momento, vêm sendo sentidas pelos profissionais em seu contexto de inserçăo,

Os impulsos em direção a progredir cientificamente foram iniciados por Florence Nightingale, que busca mudar a ênfase dada à doença, para o doente e suas necessidades.

O avanço das ciências físicas, biológicas e sociais trouxeram reflexos importantes na enfermagem levando-a a acompanhar os progressos no atendimento à saúde.

Para PIERSON (1968), à medida que a profissão evolui e amadurece, é imprescindivel que ela desenvolva um sistema de referência, um "universo de comunicaçăo", onde o grupo de conceitos possuam significados comuns para que sejam mutuamente compreensiveis por aqueles que os utilizarão, e, conseqüentemente, se evite que esta comunicação torne-se um mero jogo de palavras. Deste modo, é fundamental que todo conceito seja definido cuidadosa, sistemática e metodicamente.

No percurso de seu caminho histórico a enfermagem vem incorporando uma multiplicidade de conhecimentos de outras áreas, e com isto tambem absorvendo os diversos conceitos pertinentes a outras disciplinas.

- Enfermeira, Auxiliar de Ensino do Departamento de Enfermagem Geral e Especializada da Escola de Enfermagem de Ribeirăo Preto da Universidade de Săo Paulo.

** Enfermeira, Professor Assistente Doutor do Departamento de Enfermagem Geral e Especializada da Escola de Enfermagem de Ribeirăo Preto da Universidade de Săo Paulo.

**. Enfermeira, Professor Titular do Departamento de Enfermagem Geral e Especializada da Escola de Enfermagem de Ribeirào Preto da Universidade de Săo Paulo. 
Estabelecer conceitos proprios que permitam delimitar o seu espaço e suas fronteiras, definindo assim qual seu nivel real de aplicação prática, tem sido preocupação de vários estudiosos com a finalidade de compreender melhor o fenômeno enfermagem.

Para a profissão que se ocupa do ser humano e do seu mundo, as considerações de GREIMAS (1966) são relevantes enquanto definem o mundo humano essencialmente como o mundo da significação, e ele só pode ser chamado humano na medida em que significa alguma coisa. Segundo este mesmo autor, nas ciências humanas pode-se encontrar um denominador comum com as ciências da natureza, pois, enquanto nesta última se procura saber como são o homem e o mundo, nas ciências do homem, de modo mais ou menos explícito, se indaga sobre o que significam um e outro.

SIMŌES (1980), em seu estudo, ressalta que é indispensável e essencial ao contexto teórico e prático de uma profissão o desenvolvimento de uma terminologia básica e exclusiva.

O presente trabalho tentará conhecer e analisar um dos termos já incorporados à profissăo, dentro do Processo de Enfermagem, o Histórico de Enfermagem: como surgiu, como tem sido definido pelos autores e qual o seu significado na prática.

Não há pretensão de nossa parte em esgotar o assunto, mas somente em iniciar uma abordagem destas questões que, no futuro, merecerão, sem dúvida, discussð̃es mais aprofundadas.

Esta unificação na estrutura conceitual permitirá à profissão constituir seu corpo de conhecimentos e, assim, conquistar, de maneira efetiva, seu espaço.

\section{Surgimento do termo "Histórico de Enfermagem"}

Foi após a Segunda Grande Guerra, nas décadas de 50 e 60, com a implantação definitiva do capitalismo nos Estados Unidos da América, com a explosão do conhecimento científico; com as descobertas médicas e a maior conscientização da população sobre suas necessidades de saúde, que a enfermagem americana começou, através das Associações, Grupos e Comitês, a discutir sobre as necessidades e problemas da profissão (educação, pesquisa e prática) e a propor medidas para o seu desenvolvimento, estimulando mudanças.

O plano de cuidados surge em decorrência da preocupação em relação à sistematização do cuidado de enfermagem. Inicialmente, ele apresenta-se como um instrumento, com a finalidade de relatar e transmitir informações aos elementos que cuidavam do paciente, bem como para garantir a individualização e continuidade do cuidado. Na década de 60, o plano parece evoluir para outra dimensão, contendo objetivos dos cuidados, fundamentados em principios cientificos, e sugerindo os meios pelos quais poderão ser alcançados. Estas mudanças buscam refletir o crescimento do profissionalismo na enfermagem.

É nesta época que surge o "Processo de Enfermagem" como método de sistematização da assistência de enfermagem, operacionalizado em fases.

O alvo de nosso estudo é o termo "Histórico de Enfermagem", sendo este entendido como a primeira fase do "Processo" e cujas variaçðes na evolução histórica veremos a seguir.

Inicialmente buscamos, na produção científica nacional, identificar os autores que tratavam da sistematização da assistência de enfermagem, onde o termo "Histórico de Enfermagem" poderia ser evidenciado. 
Selecionamos para consulta os periódicos considerados mais significativos para a profissão, a saber:

—- Revista Brasileira de Enfermagem - periodo de 1962 a 1983

- Revista da Escola de Enfermagem da USP - periodo de 1967 a 1984

- Revista Enfermagem em Novas Dimensðes - período de 1974 a 1979

Nesta etapa foram catalogados seis autores que empregaram o termo.

Conforme procediamos a este levantamento, verificamos as citaçðes bibliográficas destes autores, e estas nos remeteram à literatura estrangeira, principalmente àquela dos Estados Unidos da América, na qual såo inúmeras as publicaçðes referentes à metodologias de assistência de enfermagem.

As definições apresentadas por autores estrangeiros foram selecionadas para inclusão neste trabalho à medida em que a citação original aparecia e sua consulta era possivel. Embora não constando em referências bibliográficas nacionais, outros quatros autores estrangeiros também foram consultados.

Adotamos a sequiência cronológica para apresentação das definiç̧̃es, entendendo que desta maneira poderiarnos acompanhar a evolução do termo, bem como efetuar a análise desejada.

\section{Emprego do termo pelos diferentes autores}

Etimologicamente, Histórico "é a narração cronologicamente documentada de acontecimentos passados" (SILVA 1980). Segundo FERREIRA (1967) "História é a narração metódica dos fatos notáveis ocorridos na vida da Humanidade" e Hisiórico é "relativo à história, verdadeiro".

McPHETRIDGE (1968) - "Histórico de Enfermagem é um guia que permite à enfermeira obter, de forma sistemática, informaçðes necessárias para planejar o cuidado de enfermagem. Consiste de questoes dirigidas ao paciente e espaço para as respostas. Nursing History difere da história médica já que focaliza o significado da doença e hospitalizaçào para o paciente e familia, enquanto a história médica é tomada para determinar a patologia que está presente e que serve de base para o cuidado médico".

LEWIS (1968) - "Nursing History consiste do desencadear de informaçð̃es sobre a pessoa à qual se ajuda para estabelecer sua individualidade e dar alguma indicação de suas atitudes e esforços em direção a alcançar a plenitude".

LITTLE \& CARNEVALE (1969) - "Nursing assessment ou Nursing History é a coleção de dados básicos seguidos pela formação de impressões da situação". "É a informação compacta buscando e dando transaçăo entre duas ou mais pessoas envolvendo dados subjetivos e objetivos usualmente em categorias relevantes predeterminadas para o cuidado de enfermagem".

MAYERS (1972) - "Nursing History refere-se a um conjunto de várias questoes organizadas, ou tópicos que servem de guia a fim de se obterem dados considerados necessários para planejar o cuidado do paciente. É uma parte integral da metodologia de enfermagem em direção a uma intervenção objetiva, sistemática e racional para maximizar a manutenção, o conforto e alto nível de bem-estar. Os dados são necessários para se fazer o diagnóstico de enfermagem".

YURA \& WALSH (1978) - "A fase de assessment começa com a Nursing history - cujo propósito é obter e identificar dados sobre o cliente e sua familia, que 
capacitarão a enfermeira a indicar problemas, relacionando doença e saúde. Se problemas existem, entao o primeiro passo para solucioná-los é identificá-los. Nursing history é tomada para a obtenção de dados necessários, de forma sistemática, através de uma entrevista planejada com um cliente".

CROW (1979) - "Nursing history é o meio pelo qual se coletam informaçðes sobre uma pessoa que está doente e, então, pela inspeção desta informaçăo, identificam-se, e mais tarde validam-se os problemas do paciente. Focaliza o efeito da doença e da hospitalização no paciente e em sua familia, em contraste com a história médica que focaliza a doença em si"'.

ELHART \& cols. (1983) - "A primeira fase do processo de enfermagem é a avaliação, ou seja, uma apreciação da pessoa, no seu todo, para se estabelecer uma base informativa das carências individuais da pessoa. A história colhida pela enfermeira é diferente da história clínica, pois incide fundamentalmente sobre o significado de saúde e de assistência na enfermidade, tanto para o doente como para seus familiares, como base de planejamento da assistência que o enfermeiro vai thes prestar, ao passo que a história clínica é elaborada para incluir ou excluir a patologia como base da assistência médica".

MORAES (1967) - "O levantamento dos problemas do paciente é o primeiro passo para elaboração do plano de cuidados. Deve-se observar o paciente a fim de conhecer suas necessidades; conversar com o médico para saber do programa terapêutico. Durante os cuidados prestados, manter a conversa com o paciente, $e$, a seguir, descrever as condiçōes do paciente, comportamento, história familiar e exame físico".

Para CARVALHO (1968) - "O plano de cuidados individualizado exige que a enfermeira tenha capacidade de observação e reconhecimento das necessidades de cada paciente. Este plano deve conter os dados de identificação e já estabelecer o cuidado prioritário e o grau de dependência".

HORTA (1975) - "Histórico de Enfermagem é o primeiro passo do Processo de Enfermagem: é o roteiro sistematizado para o levantamento de dados (significativos para a enfermeira) do ser humano e que tornam possivel a identificaçăo de seus problemas".

VALENTE (1974) - "Histórico de Enfermagem é o instrumento usado pela enfermeira, que consiste no registro escrito do levantamento de dados do paciente que sejam significativos para a enfermeira, tornando possivel a identificação de seus problemas que, analisados, levam ao planejamento e execução diária dos cuidados assistenciais de enfermagem".

CIANCIARULLO (1975) - "Histórico de Enfermagem é uma relação escrita de informaçðes especificas sobre o paciente, provendo dados sobre as suas necessidades ou os seus problemas como base para evolução, prescrição e avaliação da assistência de enfermagem. Difere da história clinica, pois esta dirige-se para a doença e necessidade de hospitalização. O histórico de enfermagem visa ao levantamento das necessidades e dos problemas do paciente, mesmo que não estejam relacionados diretamente à doença, com o objetivo de prestar assistência de enfermagem individualizada".

NOGUEIRA \& cols. (1978) - "Histórico de enfermagem é o levantamento e registro de dados das condiçðes psicológicas, sociais e sanitárias e das necessidades e recursos da familia".

ARAÚJO (1979) - "É o meio utilizado para obtenção de informaçðes a respeito da pessoa a ser assistida, permitindo ao profissional: conhecer, identificar e anali- 
sar as situaçð̄es apresentadas, de modo a ser planejada adequadamente a assistência de enfermagem. O levantamento de dados e a análise da situação permite a seleção dos problemas existentes e a formulação do diagnóstico de enfermagem".

PAIM (1980) - "É um relatório minucioso, claro e cronológico de informes básicos para o levantamento de problemas de enfermagem e necessidades do paciente. É indispensável para identificar os problemas e chegar ao diagnóstico".

DANIEL (1979) - "O Histórico de enfermagem consiste no levantamento sistemático de informaçðes do paciente, família e comunidade, e observaçð̃es adquiridas através do exame físico do paciente. Os dados obtidos para o histórico são registrados em um formulário e analisados com a finalidade de identificar problemas que levam à determinação do diagnóstico de enfermagem".

\section{O significado de "Histórico de Enfermagem"}

Ao analisarmos as definiçðes apresentadas por estes autores, alguns aspectos chamam atenção e merecem destaque.

Em um primeiro momento, nota-se uma preocupação acentuada em se diferenciar o histórico de enfermagem da história clínica, o que nos parece ser uma tentativa de desvincular a enfermagem do saber médico, atribuindo-se, a cada um deles, objetivos especificos, tentando-se, desta forma, dar corpo próprio ao saber de enfermagem.

Estas observaçðes são comprovadas quando HORTA (1979) expðe que, no Brasil, o Histórico de Enfermagem recebe inicialmente o nome de Anamnese de Enfermagem, porém, devido à forte conotação médica que o termo transmitia, procurou-se outra denominação.

Ao se observar a evolução das publicações acerca do Processo de Enfermagem como Metodologia de Assistência, MORAES (1979) e CARVALHO (1968) consideram ser o "Levantamento dos problemas do paciente o primeiro passo para a elaboração do plano de cuidados" e que exige da enfermeira "capacidade de observação de reconhecimento das necessidades de cada paciente". Estas autoras não mencionam o termo Histórico de Enfermagem, embora o significado expresso em levantamento de dados, posteriormente, passe a ser relacionado ao mesmo.

O significante Histórico de Enfermagem divulgado por HORTA (1974) mantém o significado de "roteiro sistematizado para levantamento de dados...". Isto também se observa nas publicações de VALENTE (1974), NOGUEIRA \& cols. (1979) e de DANIEL (1979).

A utilização, pelos autores mencionados, do termo "Levantamento de Dados" aproxima-se do conceito apresentado por FERREIRA (1967), significando "o conjunto de operaçōes para determinar as características de um fenômeno".

As alteraçoes de significantes e significados no decorrer do tempo, buscam delimitar a abrangência e especificidade desta etapa do Processo de Enfermagem com a finalidade de viabilizar a sua operacionalização.

$\dot{A}$ medida que analisamos as palavras empregadas para definirem o Histórico de Enfermagem, observamos que algumas descrevem o conteúdo da etapa como em MAYERS (1972) “... um conjunto de várias questð̋es organizadas, ou tópicos, que servem de guia para a obtenção de dados..."; outras apresentam seu objetivo ou finalidade, observados em YURA \& WALSH (1978) “... cujo propósito é obter e 
identificar dados sobre o paciente...". Além daquelas que nos detalham a forma de apresentaçåo, "... é um guia..." (McPHETRIDGE, 1968); ou ainda como "... é roteiro..." (HORTA, 1974); e finalmente como "... é um relatório minucioso..." (PAIM, 1980).

Pelas definiçðes apresentadas, é possivel delinear-se o consenso existente entre os autores de que o Histórico de Enfermagem é um instrumento a ser utilizado pelo enfermeiro para levantar dados do paciente, e que favorece uma interação efetiva entre ambos.

Verifica-se, então, diante dos diversos conceitos, e considerando-se as palavras empregadas, que a etimologia do termo "Histórico" não está sendo respeitada.

Em âmbito nacional, a difusāo da proposta de HORTA (1974) sobre o Histórico de Enfermagem tem sido adotada como referencial pelos demais autores, existindo poucas evidências, na literatura pesquisada, de questionamentos sobre esta proposta.

$\mathrm{Na}$ literatura estrangeira, em especial a norte-americana, surgiram dúvidas quanto ao emprego do Nursing Assessment e Nursing History*

BLOCH (1974), ao considerar alguns problemas da terminologia em enfermagem, sugere que o Assessment em Enfermagem seja definido em dois processos separados: o primeiro, a coleta de dados, que consistirá da reunião de, mais ou menos, fatos objetivos sem um componente interpretativo. O segundo, a definiçăo do problema, onde o julgamento é feito através da análise critica e interpretação dos dados.

LITTLE \& CARNEVALE (1969) utilizam Nursing Assessment e Nursing History com o mesmo significado.

Nursing History é tratado como Assessment Guide por MAYERS (1972), sem distingüi-lo como etapa.

YURA \& WALSH (1978) incluem o Nursing History como o primeiro passo dentro da fase de Assessment.

CROW (1979) identifica Assessment como primeiro estágio do Processo de Enfermagem, sendo ele constituido de duas partes. A primeira é a "coleta de informaçðes sobre a pessoa que está doente e é usualmente feita por meio de Nursing History". A segunda, é alcançada através da inspeção das informaçðes obtidas, onde os problemas são identificados e validados.

Para LEWIS (1968), Nursing History é um passo dentro do Assessment. Este entendimento, a nosso ver, configura a idéia prevalecente nas definiçðes de autores estrangeiros.

De modo geral, constatamos predominância, entre os autores, de que o Histórico de Enfermagem constitui a primeira fase de um processo. É evidenciado que nesta fase são coletados dados sobre o paciente, e estes, após análise, permitirão a identificação dos problemas e a determinação do diagnóstico de enfermagem, fornecendo conseqüentemente subsídios para a elaboração do plano de cuidados.

O significado portanto existe, apresenta certa homogeneidade entre os autores e mantém sua especificidade junto à comunidade de enfermagem. Na verdade, o que tem diferido é o significado etimológico do termo, que nem sempre se preocupa com a "narração cronológica de acontecimentos passados", SILVA (1980), valorizando mais os fatos presentes.

\footnotetext{
- Devido à dificuldade na tradução, de maneira apropriada, dos termos Nursing Assessment e Nursing History, eles foram mantidos na sua forma original.
} 
Observa-se que, historicamente, ocorreram mudanças em relaçăo ao significante, que, se no início está oculto, com o desenvolvimento de metodologias de Assistência de Enfermagem, surge com o nome de Anamnese e, posteriormente, firma-se como Histórico de Enfermagem.

\section{CONSIDERAÇOESS FINAIS}

Segundo BLOCH (1974), a definiçăo de termos é essencial para clarificar o significado dos passos do Processo de Enfermagem, e decisiva ao se testarem pesquisas na prática.

O significante Histórico de Enfermagem, bem como seu significado, ou seja, sua representação na linguagem, já foram incorporados à profissảo, cujo contexto e situaçào condicionam o resultado da relação significante/significado, estabelecendo desta maneira a sua significação.

Mediante este referencial e pela análise realizada observa-se que objetivos, finalidade, conteúdo e forma não comunicam "a real significaçåo do Histórico de Enfermagem" * com exceção feita por ELHART \& cols. (1983), cuja definição avança em direção à essência do termo quando afirmam que a "primeira fase do processo de enfermagem é a avaliaçåo, uma apreciaçào da pessoa na sua totalidade visando estabelecer bases informativas sobre suas carências individuais".

SIMŐES (1980) discute a definição de HORTA (1974), quando salienta que " "não há preocupação primordial de se fazer uma disposição cronológica de fatos, mas, muito mais de se descrever a situação/problema que se apresenta". Sugere, ainda, que se reflita sobre a substituição do "Histórico de Enfermagem" por "Descrição da situação do cliente".

$O$ teor das definiçoes também permite-nos concluir que elas nåo demonstram relação com a etimologia da palavra Histórico, como já dissemos anteriormente, pois nåo se evidencia "narração cronológica dos fatos".

Qualquer que seja a Metodologia de Assistência de Enfermagem adotada, a primeira fase constituir-se-á da descrição da situação/p̧roblema, exigindo correlaçăo de dados, análise e interpretação. Esta etapa é fundamental para a operacionalização dos demais passos.

Em nossa vivência na área assistencial, ao falarmos em Histórico de Enfermagem, vem-nos à mente uma etapa do Processo de Enfermagem, pela qual o enfermeiro contactua com o paciente, entrevista-o, colhe dados, analisa-os, interpreta-os, a fim de programar a assistência de enfermagem. Entretanto, análise e interpretação são tarefas que exigem do enfermeiro conhecimentos teóricos e habilidades que, na maioria das vezes, ele não possui. Como consequêencia, este primeiro passo do Processo não é desenvolvido na sua totalidade, permanecendo em nivel superficial, repercutindo nos passos seguintes, dificultando-os.

Finalizando, consideramos de suma importância que outros estudos sobre a Terminologia em enfermagem sejam aprofundados para que realmente o "universo de comunicação" entre seus profissionais torne-se coerente e compreensível e que a relação de seus significantes/significados atinjam a essencialidade de seus conceitos.

Grifo nosso. 
ANSELMI, M.L.; CARVALHO, E.C.; ANGERAMI, E.L.S. Understanding and clinical utilization of the term Nursing History. Rev. Esc. Enf. USP, Săo Paulo, 22(2):181-188, Aug. 1988.

The present study approaches the problem of terminology in nursing and its use in practice. It deals primordially with term Nursing History analyzing its origin and its meanings.

UNITERMS: Nursing assessment. Nursing process.

\section{REFERENCIAS BIBLIOGRÁFICAS}

1. ARAÚJO,O.M.M. de Consulta de enfermagem à gestante. Rev. Bras. Enf., Brasilia, 32(3):259-70, jul./set. 1979

2. BLOCH, D. Some crucial terms in nursing what do they really mean? Nurs. Outlook, New York 22(11):689-694, Nov. 1974.

3. CARVAlHO, A.C. de Plano de cuidados de enfermagem como uma das funçoes da enfermeira chefe. Rev. Esc. Enf. USP, Såo Paulo, 2(1):108-118, mar. 1968.

4. CIANCIARULLO, T.I. O histórico de enfermagem: subsidios para sua introduçăo no hospital. Rev. Esc. Ent. USP, Sto Paulo, 10(2):219-229, ago. 1975.

5. CROW, J. Assessment. IN: KRATZ, C. The nursing process. London, Bailliere Tindall, 1979

6. DANIEL, L.F. A enfermagem planejada. 2! ed. Sào Paulo, Cortez, 1979.

7. ELHART, D. et alii. Principios clentificos de enfermagem. 8: ed., Lisboa, Editora Portuguesa de Livros Ténicos e Cientificos, 1983.

8. FERREIRA, A.B. de H. Pequeno diciondrio brasileiro de lingua portuguesa. 11: ed. Rio de Janeiro, Civilizaçăo Brasileira, 1967.

9. GREIMAS, A.J. Semintica estrutural. Sảo Paulo, Cultrix, 1973.

10. HORTA, W.A. O processo de enfermagem: fundamentaçăo e aplicaçăo. Enf. Novas Dimens., Săo Paulo, 1(1):10-16, mar./abr. 1975

11. LEWIS, L. This 1 believe... about the nursing process: key to care. Nurs. Outlook, New York, 16:26-29, May 1968.

12. LITTLE, D'. \& CARNEVALE, D.L. Nursing care planning. Philadelphia, Lippincott, 1969.

13. MAYERS, M.G. A sistematic approach to nursing care. New York, Appleton-Century-Crofts, 1972.

14. McPHETRIDGE, M. Nursing history: one means to personalize care. Am. J. Nurs., New York, 68(1):68-75, Jan. 1968.

15. MORAES, E. Plano de cuidados de enfermagem. Rev. Esc. Enf. USP, São Paulo, l(1):99-111, out . 1967.

16. NOGUEIRA, M.J.E. et alii. Modelo de histórico e plano de assistência de enfermagem à família. Rev. Esc. Enf. USP, Såo Paulo, 12(1):17-60, abr. 1978.

17. PAIM, R.C.N. Metodologia cientifica em enfermagem. Rio de Janeiro, 1980.

18. PIERSON, D. Teoria e pesquisa em sociologia. 11? ed. Sảo Paulo, Melhoramentos, 1968.

19. SILVA, A.M. Dicionário da Lingua Portuguesa. apud. SIMÕES, C. Contribuiçăo ao estudo da terminologia básica de enfermagem no Brasil: taxionomia e conceituaçào. Bauru, 1980. (Dissertaçăo de mestrado Escola de Enfermagem Ana Neri da UFRJ).

20. SIMŌES, C. Contribuiçăo ao estudo da terminologia básica de enfermagem no Brasil: taxionomia e conceituaçào. Bauru, 1980. (Dissertaçăo de mestrado - Escola de Enfermagem Ana Neri da UFRJ).

21. VALENTE, M.A. Estudo da identificaçăo dos problemas de enfermagem em pacientes hospitalizados com pneumopatias. Rev. Esc. Enf. USP, Sào Paulo, 8(2):141-198, ago. 1974.

22. YURA, H. \& WALSH, M. The nursing process: assessing, planing, implementing, evaluating, 3: ed. New York, Appleton-Century-Crofts, 1978

Recebido para publicaçào em 19/3/87.

Aprovado para publicaçăo em 20/4/88. 